This is the final peer-reviewed accepted manuscript of:

Del Rey, R., Casas, J. A., Ortega-Ruiz, R., Schultze-Krumbholz, A., Scheithauer, H., Smith, P., Thompson, F., Barkoukis, V., Tsorbatzoudis, H., Brighi, A., Guarini, A., Pyżalski, J., \& Plichta, P. (2015). Structural validation and cross-cultural robustness of the European Cyberbullying Intervention Project Questionnaire. Computers in Human Behavior, 50, 141-147.

The final published version is available online at:

https://doi.org/10.1016/j.chb.2015.03.065

Rights / License:

The terms and conditions for the reuse of this version of the manuscript are specified in the publishing policy. For all terms of use and more information see the publisher's website. 


\title{
Structural validation and cross-cultural robustness of the European Cyberbullying Intervention Project Questionnaire
}

\author{
Rosario Del Rey ${ }^{a}$, José A. Casas ${ }^{\mathrm{b}, *}$, Rosario Ortega-Ruiz ${ }^{\mathrm{b}, \mathrm{c}}$, Anja Schultze-Krumbholz ${ }^{\mathrm{d}}$, \\ Herbert Scheithauer ${ }^{\mathrm{d}}$, Peter Smith ${ }^{\mathrm{e}}$, Fran Thompson ${ }^{\mathrm{e}}$, Vassilis Barkoukis ${ }^{\mathrm{f}}$, Haralambos Tsorbatzoudis ${ }^{\mathrm{f}}$, \\ Antonella Brighi $^{\mathrm{g}}$, Annalisa Guarini ${ }^{\mathrm{g}}$, Jacek Pyżalski ${ }^{\mathrm{h}}$, Piotr Plichta ${ }^{\mathrm{i}}$
}

${ }^{a}$ University of Seville, Spain

${ }^{\mathrm{b}}$ University of Córdoba, Spain

${ }^{c}$ University of Greenwich, United Kingdom

${ }^{\mathrm{d}}$ Freie Universität Berlin, Germany

${ }^{\mathrm{e}}$ Goldsmiths, University of London, United Kingdom

${ }^{\mathrm{f}}$ Aristotle University of Thessaloniki, Greece

${ }^{\mathrm{g}}$ University of Bologna, Italy

${ }^{\mathrm{h}}$ Adam Mickiewicz University, Poland

${ }^{\mathrm{i}}$ University of Wrocław, Poland

\section{A R T I C L E I N F O}

\section{Article history:}

\section{Keywords:}

Cyberbullying

Validation

Questionnaire

Confirmatory factor analysis

\begin{abstract}
A B S T R A C T
During the last decade, cyberbullying has become an increasing concern which has been addressed by diverse theoretical and methodological approaches. As a result there is a debate about its nature and rigorously validated assessment instruments have not yet been validated. In this context, in the present study an instrument composed of 22 items representing the different types of behaviours and actions that define cyberbullying has been structurally validated and its cross-cultural robustness has been calculated for the two main dimensions: cyber-victimization and cyber-aggression. To this end, 5679 secondary school students from six European countries (Spain, Germany, Italy, Poland, United Kingdom, and Greece) were surveyed through this self-report questionnaire which was designed based on previously existing instruments and the most relevant conceptual elements. Exploratory and confirmatory factor analyses were conducted and the global internal consistency was computed for the instrument and its two dimensions. Identical factor structures were found across all of the six subsamples. The results contribute to existing research by providing an instrument, the European Cyberbullying Intervention Project Questionnaire, which has been structurally validated in a wide sample from six different countries and that is useful to evaluate psycho-educative interventions against cyberbullying.
\end{abstract}

\section{Introduction}

In recent years, society has shown a growing interest in the phenomenon named cyberbullying frequently appearing in the online social relationships among youngsters and adolescents (Fenaughty \& Harré, 2013). Nowadays, we are immersed in the process of elaborating a solid theoretical approximation and an agreed definition of the phenomenon (Berne et al., 2013;

\footnotetext{
* Corresponding author at: University of Córdoba, Department of Psychology, Avda, San Alberto Magno S/N, 14004 Córdoba, Spain. Tel.: +34 957212604.

E-mail address: jacasas@uco.es (J.A. Casas).
}

Tokunaga, 2010). Thus, one of the main guides to follow is the research developed around traditional bullying (Olweus, 2013) as cyberbullying is defined as bullying developed through electronic media (Vivolo-Kantor, Martell, Holland, \& Westby, 2014). Traditional bullying has been defined as physical, verbal, social and/or psychological aggression by a pupil against another, whom is chosen to be a victim of repeated attacks (Olweus, 1993, 1999). Such a negative and intentioned action puts the victim in a situation that is difficult to get out of. Bullying is neither an isolated aggression nor a simple individual behaviour but an interactive phenomenon in which several subjects are involved in at least three roles: bully, victim and bully-victim. Its distinctive characteristics are: the intentionality to hurt someone else, the imbalance of 
power between the aggressor and the victim and the repetition of the aggressive conducts by the aggressors over their victims. Such scientific evidences have clarified the nature of the bullying phenomenon and determined its standardization, hence, the appearance of instruments to measure it (Greif \& Furlong, 2006).However, the nature of the electronic means that characterizes cyberbullying has made it necessary to investigate not only its conceptualization but also in order to provide instruments suitable to its nature with the aim of showing the levels of prevalence among adolescent population (Vivolo-Kantor et al., 2014).

\section{Cyberbullying: Definition and characteristics}

Behaviours such as verbal attacks through digital devices, publication and exhibition of embarrassing pictures, and the exclusion from online communication are some examples of how traditional bullying brings to life cyberbullying. Other behaviours such as virtual identity theft (i.e. to impersonate someone else or to hack personal accounts with the aim of obtaining personal information) are not included in traditional forms of bullying but are considered as cyberbullying (Perren et al., 2012). Instead, virtual behaviours accompanied by certain nuances such as the presence of adults take advantage of minors, or the intentionality of sexual nature to obtain embarrassing pictures (Smith, Thompson, \& Davidson, 2014), are linked to other phenomena different from cyberbullying such as grooming or sexting (Den Hamer \& Konijn, 2015).

Cyberbullying, by mainly referring to traditional bullying researches (Slonje \& Smith, 2008), is defined as a clearly intentional aggression or hostile or harmful act carried out through an electronic device repeatedly over time by setting up an imbalance of powers between the aggressor and the victim (Tokunaga, 2010). Accordingly, both the aggressor and the victim are, a priori, substantial characters of the phenomenon, but there are also those that are aggressors and victims at the same time, the bully-victims (Yang \& Salmivalli, 2013). In addition, there are researches that identifies cyberbullying exclusively with cyber-aggression (Calvete, Orue, Estévez, Villardón, \& Padilla, 2010) or with cybervictimization (Müller, Pfetsch, \& Ittel, 2014), leaving out the dynamic existing between the roles and how the criteria of intentionality, repetition and imbalance of powers takes place between them (Olweus, 2013). Criteria that otherwise are not as evident in cyberbullying as they are in traditional bullying (Dehue, 2013; Slonje, Smith, \& Frisén, 2013; Smith, Del Barrio, \& Tokunaga, 2013). In this respect, some authors suggest that a single image or any other humiliating audio-visual material can be comparable to the repetition of traditional bullying, since the content can be perpetual on the Internet and is available for any person seeking access to it, or may even be downloaded and stored on personal devices (Heirman \& Walrave, 2008), this suggests that digital aggression is equally harmful. Concerning the imbalance of power, high levels of technological knowledge and the difficulties that the victims may have in identifying the aggressors, can be interpreted as inferiority before the aggressor (Menesini \& Nocentini, 2009; Vandebosch \& Van Cleemput, 2008).

Despite these considerations, from our point of view, repetition shall be considered as a requirement for cyberbullying as for the victim or even for both the aggressor and the victim the experience is a repeated behaviour. In fact, certain existing qualitative studies have shown the need to maintain such a criterion (Nocentini et al., 2010). With regard to the imbalance of power, there is no doubt of its relevance in the dynamic of the phenomenon as the lack of competence for keeping personal data secure in digital scenarios imply or may imply that the victim faces inferiority with respect to the aggressor when communicating through digital devices (Vandebosch \& Van Cleemput, 2008).

\section{Prevalence of cyberbullying}

There are currently more than 300 articles published about cyberbullying which offer figures about its prevalence (Arsène \& Raynaud, 2014). However, there are differences in these results which make it difficult to know how many people are affected by this problem (Modecki, Minchin, Harbaugh, Guerra, \& Runions, 2014). Thus, among the researches referring only to cyberaggression, figures range from 5.3\% to $31.5 \%$ (Gradinger, Strohmeier, \& Spiel, 2009; Pornari \& Wood, 2010). Among those referring only to cyber-victimization figures oscillate between $2.2 \%$ to $56.2 \%$ (Perren, Dooley, Shaw, \& Cross, 2010). These differences are also present in researches that analyze both cyber-aggression and cyber-victimization. For instance, a Greek study found $28.3 \%$ of cyber-victims of cyberbullying and $14.6 \%$ of perpetrators (Floros, Siomos, Fisoun, Dafouli, \& Geroukalis, 2013). However, another in Sweden found that $5 \%$ were cyber-victims and $4 \%$ were cyberbullies (Låftman, Modin, \& Östberg, 2013). The differences can be found even in studies developed with a population of similar characteristics and in the same regions or countries (Baek \& Bullock, 2014).

Such a diversity in the rates of prevalence may have its origin, among others, in the plethora of perspectives from which cyberbullying is analyzed (Sabella, Patchin, \& Hinduja, 2013) and therefore, in the great differences existing between the instruments used (Modecki et al., 2014), this diversity is inherited from traditional bullying measurements (Greif \& Furlong, 2006).

\section{Measures of cyberbullying}

As mentioned above, cyberbullying involves a diversity of elements and behaviours making research and the development of valid assessment instruments more complicated (Ybarra, Mitchell, \& Korchmaros, 2011). This difficulty has been partially overcome in recent studies which focus on the development of measurement instruments, but have exclusively dealt with only one of the dimensions so far: cyber-aggression (Calvete et al., 2010; Law, Shapka, Hymel, Olson \& Waterhouse, 2012) or cybervictimization (Tynes, Rose, \& Williams, 2010), separately. Although this is a great contribution to existing research, studying only part of the phenomenon omits the dynamic nature of cyberbullying, and means it is not sufficient to test its complexity with the respective instruments (Dempsey, Sulkowski, Nichols, \& Storch, 2009).

In the latest systematic review of measurement instruments of cyberbullying, Berne et al. (2013) have found 44 different instruments (until October 2010) which have been used to evaluate, measure or analyse this phenomenon. The vast majority of these instruments are self-reports focussing on different aspects of cyberbullying, with $56 \%$ of them assessing cyber-aggression or cyber-victimization separately (Berne et al., 2013). These two aspects are addressed together only in the Italian studies of Menesini, Nocentini, and Calussi (2011). However, the whole model did not fit and, therefore, the validation of the instrument had to be made separately for cyber-aggression and cyber-victimization. The $40 \%$ of remaining instruments focus on other elements such as the type of devices that can carry out an attack or on cyberabuse (Law, Shapka, Domene, \& Gagné, 2012).

In regards to specific psychometric properties, only $22 \%(N=10)$ of all the instruments analysed used statistical methods to empirically examine the underlying theory, such as confirmatory factor analysis (Berne et al., 2013). In most cases, these structural validations have been performed with samples of approximately 500 participants, with the exception of the study by Ybarra and Mitchell (2008) which was carried out with 1700 people through an online survey about cyber-victimization. 
Moreover, these examples each come from one particular locality, region or country. There are no records of structural validations in which both dimensions (cyber-aggression and cyber-victimizations) are included, which is essential if it is assumed that cyberbullying is a dynamic between the aggressor and the victim. There is not, the cross-cultural robustness analysis in researches in which there has been collaboration from different countries (Berne et al., 2013; Byrne \& Campbell, 1999). Therefore, we still face significant limitations to describe the cyberbullying phenomenon as no comparable figures of prevalence can be shown (Baek \& Bullock, 2014). In this regard, it is still pending the task of creating instruments, validated with samples from different countries, which allow us to know if the phenomenon is more prevalent in certain countries. In addition, it is also pending and analysis of whether the dynamic between the cyber-aggressor and the cyber-victim become a part or cyberbullying or not.

\section{Objetive}

In this respect, the goal of the present study was to look for the structural validation and the cross-cultural robustness of an instrument for cyberbullying that, considering the dynamic nature of the phenomenon, includes cyber-aggression and cybervictimization behaviours. We understand that this is a modest step in the research of study and intervention against cyberbullying.

\section{Materials and methods}

\subsection{The sample group}

The whole sample was composed of 5679 students from six European countries: Poland $[N=900 ; 15.8 \%$ (52.3\% girls), 8 schools], Spain $[N=859 ; 15.1 \%$ (52.3\% girls), 3 schools], Italy $[N=1,430 ; 25.2 \%$ (56.3\% girls), 15 schools], United Kingdom [ $(N=737 ; 13 \%$ (44.6\% girls), 5 schools], Germany $[N=846 ; 14.9 \%$ (49\% girls), 5 schools] and Greece [ $N=907 ; 16 \%$ (54.2\% girls), 13 schools]. $49 \%$ percent were girls and participants' age was between 11 and 23 years ( $M=14.77 ; S D=1.58$; 7 th to 10 th grades). The selection of the sample was made through an incidental design by accessibility of those schools that accepted to participate in this study.

\subsection{Measure}

The European Cyberbullying Intervention Project Questionnaire (ECIPQ; Brighi et al., 2012) composed 22 Likert type items with five options for frequency ranging from 0never to more, 1 once or twice, 2 once a month, 3 once a week, 4 more times a week. This questionnaire was designed on the basis of previous measures by Dooley, Pyżalski, and Cross (2009) and Pyzalski (2012) to evaluate the two dimensions of cyberbullying - victimization and aggression. It also tries to include the cyberbullying criteria of repetition and, although implicitly, the imbalance of power as it includes items of behaviours which imply a technological domain of the aggressor and a lack of the use of security measures by the victim. For instance, Someone hacked into my account and pretended to be me. The 22 items are given in the Appendix.

\subsection{Procedure and data analysis}

A purposive sampling procedure was used. The first version of the questionnaire was designed in English, translated into each of the five other languages, and a back translation checked against the original.
At first, descriptive analyses in the total sample and by participant countries were performed. Additionally, due to the ordinal nature of the variables rank-base comparative analyses were also performed with the aim of contrasting the differences among the subsamples.

A cross-validation process was performed by randomly dividing the sample into two same-size subsamples: S1 $(n=2820)$ and S2 $(n=2859)$. The first subsample was employed to identify the number of underlying factors; in this study the two factors of victimization and aggression. This was done by means of an exploratory factor analysis (EFA) carried out using FACTOR 9.2 (Lorenzo-Seva \& Ferrando, 2006). This program was used to generate a matrix of polychoric inter-item correlations which were then subjected to EFA. The decision to compute polychoric correlations was based on recognition that the ECIPQ employs a polytomous response format and provides ordinal rather than interval-level measurement (Flora, Finkel, \& Foshee, 2003). A polychoric correlation is a more appropriate measure of the relationship between two Likert-type items than Pearson correlation (Flora \& Curran, 2004; Jöreskog, 1994; Olsson, 1979). This is because a set of Likert-type items does not have a multivariate-normal distribution and the normal-theory maximum likelihood method of factor estimation that is typically employed in EFA is not the best method of estimation for assessing the factor structure of such variables, even when applied to a matrix of polychoric correlations (Bollen, 1989; Browne \& Cudeck, 1993). Unweighted least squares (ULS) served as the extraction technique because it is robust for use with data that are not normally distributed. Finally, the rotation was set to direct oblimin because total scores on the victimization and aggression subscales were inter-correlated.

The second subsample was used to verify the goodness of fit of the factor structure that emerged from the first exploratory analysis and to test for invariance across the different countries. Confirmatory factor analysis (CFA) was carried out using LISREL 9.1 (Jöreskog \& Sörbom, 2012). As the data are ordinal and the correlations between factors are high, the Diagonally Weighted Least Squares (DWLS) method was used (Flora \& Curran, 2004; Holgado-Tello, Chacón-Moscoso, Barbero-García, \& Vila-Abad, 2010; Morata-Ramírez \& Holgado-Tello, 2013). We followed the recommendations of $\mathrm{Hu}$ and Bentler (1999) to compare the suitability of the models proposed, using the comparative fit index (CFI), the goodness of fit index (GFI), and the non-normed fit index (NNFI), with values above .95 (Bentler \& Bonett, 1980). The root mean square error of approximation (RMSEA) should be less than .05; SRMR values less than .08 were considered acceptable and those below .05 as adequate (Hu \& Bentler, 1995). In order to investigate the stability of the confirmatory factor analysis under cross-validation, and to avoid splitting the available data, the expected cross-validation index (ECVI) was used (Browne \& Cudeck, 1993). The ECVI measures the discrepancy between the fitted covariance matrix in the analysed sample and the expected covariance matrix that would be obtained in another sample of equivalent size. Application of the ECVI assumes a comparison of models, whereby the model having the smallest ECVI exhibits the greatest potential for replication (Byrne, 2006). The selection of these indices and their cut off values was based on their performance with large samples and DWLS as estimation method (Wu, West, \& Taylor, 2009).

For calculating the prevalence of cyberbullying, the roles of behaviours participation and repetition were considered. Thus, Cyber-victims have been identified with scores equal or higher than 2 (once a month) in any of the items of cyber-victimization and with scores equal or lower that 1 (once or twice) in all of the items of aggression. In addition, Cyber-aggressors are those subjects with scores equal or higher than 2 (once a month) in any of the items of cyber-aggression and equal or lower that 1 (once or twice) in all of 
the items of cyber-victimization. Cyber-bully/Victim have been identified those subjects with a score in any of the items of both cyber-aggression and cyber-victimization with a score equal or higher than 2 (once a month).

\section{Results}

\subsection{Descriptive analysis}

The Kruskal-Wallis test has been performed with the aim of comparing the differences among the participant countries with regard to the two dimensions of the questionnaire, cyber-aggression and cyber-victimization, and to the total questionnaire. Differences among participant countries were found (see Table 1).

\subsection{Exploratory factor analysis}

In the EFA with subsample S1 the variables violated the assumption of multivariate normality (see Table 2), Mardia's coefficient $=777.18$. The Kaiser-Meyer-Olkin of Sampling Adequacy (KMO) value was .832 and Bartlett's Test of Sphericity $\chi^{2}$ : $71170.0(d f=231 ; p<.001)$. The factors were subjected to a direct oblimin rotation and the analysis revealed that the extraction of two factors was appropriate (see Table 2). The variance accounted for by the two factors was $65.4 \%$. Also, Bentler's simplicity (S) index (1977) and the loading simplicity (LS) index (Bentler, 1977; Lorenzo-Seva, 2003) were computed with values of .99 and .75, respectively, which means that each item was mainly related to only one dimension, and the overall solution showed high factor simplicity. The inter-factor correlation is .765.

\subsection{Confirmatory factor analysis}

According to the EFA results, a two-factor model could be an adequate approximation of the data. The CFA was conducted with the conditions outlined above because of the violation of the assumptions of normality and kurtosis with Mardia's coefficient $=629.17$. The results of fitting the two-factor solution are suitable in sample $\mathrm{S} 2$ and in each subsample from the six countries in which the instrument was evaluated (see Table 3, Fig. 1).

The results show that all models have CFI values greater than 0.95 and the ECVI index value does not exceed 0.6. Based on these low values of ECVI and adequacy of CFI values, the suitability of the model for different samples can be assumed. Both these indices are used to measure the comparative fit between two or more models, and the smaller the obtained values the better the fit (Bandalos, 1993). Our study, with the large sample employed and the need to compare more than three groups, is unsuited for the chi square difference test (Browne \& Cudeck, 1993; Satorra \& Bentler, 2001). This test has the same limitations as the likelihood ratio test in general, so that very large samples lead to very trivial difference tests. As to the reliability of the instrument, the indices obtained (McDonald's Omega $=.99$ and Standardized Cronbach's alpha $=.96)$ exhibit a suitable over all reliability and also adequate
Table 2

Descriptive univariate analysis and factor loadings.

\begin{tabular}{lccllll}
\hline & M & SD & Skewness & Kurtosis & Factor 1 & Factor 2 \\
\hline CybV1 & .27 & .645 & 3.305 & 13.362 & .359 & \\
CybV2 & .23 & .606 & 3.441 & 14.298 & .498 & \\
CybV3 & .12 & .471 & 5.347 & 34.466 & .427 & \\
CybV4 & .13 & .492 & 5.015 & 30.112 & .408 & \\
CybV5 & .22 & .489 & 3.051 & 14.493 & .520 & \\
CybV6 & .08 & .384 & 6.101 & 43.589 & .849 & \\
CybV7 & .10 & .448 & 5.646 & 36.979 & .866 & \\
CybV8 & .13 & .463 & 4.629 & 26.313 & .698 & \\
CybV9 & .09 & .398 & 6.318 & 47.837 & .793 & \\
CybV10 & .11 & .424 & 5.447 & 36.627 & .687 & \\
CybV11 & .15 & .509 & 4.704 & 26.398 & .883 & .782 \\
CybB1 & .22 & .623 & 3.934 & 17.955 & & .800 \\
CybB2 & .17 & .562 & 4.427 & 22.986 & & .945 \\
CybB3 & .10 & .492 & 6.096 & 40.367 & & .910 \\
CybB4 & .09 & .487 & 6.284 & 42.252 & & .882 \\
CybB5 & .09 & .471 & 6.499 & 46.054 & & .828 \\
CybB6 & .10 & .490 & 6.147 & 41.200 & & .819 \\
CybB7 & .08 & .463 & 6.788 & 48.921 & & .859 \\
CybB8 & .09 & .443 & 6.500 & 47.670 & & .865 \\
CybB9 & .07 & .408 & 7.486 & 62.431 & & \\
CybB10 & .22 & .678 & 3.881 & 16.329 & & \\
CybB11 & .08 & .443 & 6.746 & 49.208 & & \\
\hline
\end{tabular}

Table 3

Model Fit subsample S2 and six countries.

\begin{tabular}{lllllllll}
\hline & $\chi^{2}$ & df & GFI & CFI & NNFI & RMSEA & SRMR & ECVI \\
\hline$\quad$ Total & 1484.15 & 208 & .986 & .993 & .993 & .030 & .080 & .505 \\
$\quad$ Sample & & & & & & & & \\
$\quad$ S2 & & & & & & & & \\
Poland & 452.42 & 208 & .992 & .994 & .993 & .010 & .058 & .664 \\
Spain & 375.35 & 208 & .973 & .978 & .975 & .020 & .055 & .677 \\
Italy & 581.63 & 208 & .966 & .988 & .987 & .051 & .087 & .699 \\
UK & 525.71 & 208 & .958 & .952 & .947 & .010 & .072 & .684 \\
Germany & 389.59 & 208 & .989 & .996 & .994 & .047 & .021 & .600 \\
Greece & 395.56 & 208 & .991 & .989 & .981 & .013 & .010 & .654 \\
\hline
\end{tabular}

reliability of each of the two factors making up the scale, the cybervictimization factor with $\alpha=.97$ and the aggression factor with $\alpha=.93$.

Finally, for calculating the prevalence of involvement in cyberbullying, subjects were selected on the basis of the above-cited theoretical criterion. Such a selection was developed with the whole sample and with the subsamples comprising each of the participant countries (see Table 4).

\section{Discussion}

The study achieved the intended goal of the structural validation of an instrument on cyberbullying that integrates the traditional bullying characteristics, the dimensional nature of the phenomenon including both cyber-victimization and cyberaggression bearing in mind the diversity of cyberbullying behaviours based on the concepts of Olweus (2012) and Smith et al.

Table 1

Kruskal-Wallis test

\begin{tabular}{|c|c|c|c|c|c|c|c|}
\hline & Country & $N$ & Mean rank & & Mean Rank & & Mean Rank \\
\hline \multirow[t]{7}{*}{ Total sacale } & Poland & 900 & 2697.09 & Cyber agression & 2906.57 & Cyber Victim & 2599.78 \\
\hline & Spain & 859 & 2509.55 & & 2681.66 & & 2528.01 \\
\hline & Italy & 1430 & 3183.37 & & 3230.88 & & 3072.31 \\
\hline & UK & 737 & 2334.24 & & 2312.35 & & 2549.22 \\
\hline & Germany & 846 & 2545.05 & & 2830.72 & & 2497.55 \\
\hline & Greece & 907 & 3439.48 & & 2745.03 & & 3563.27 \\
\hline & & \multicolumn{2}{|c|}{$\chi^{2}=350.60 p=.00$} & $\chi^{2}=247.21 p=.00$ & & $\chi^{2}=363.90 p=.00$ & \\
\hline
\end{tabular}




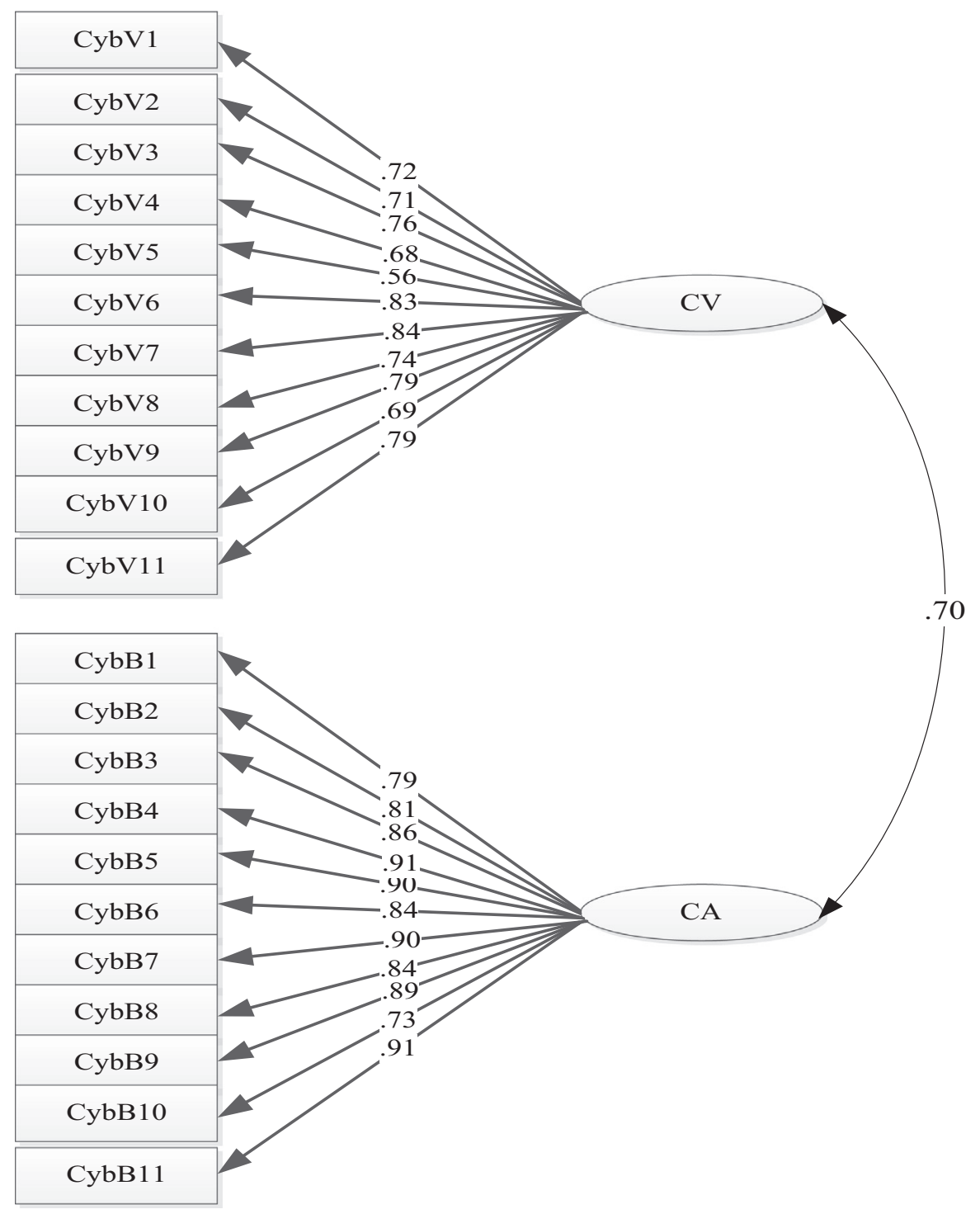

Fig. 1. AFC Graphic solution.

Table 4

Prevalence of cyberbullying.

\begin{tabular}{|c|c|c|c|c|c|}
\hline Country & $N$ & Victims $(N, \%)$ & Aggressors $(N, \%)$ & Bully/Victims $(N, \%)$ & Total implication $(N, \%)$ \\
\hline Poland & 900 & $55(6.11 \%)$ & $61(6.77 \%)$ & $36(4 \%)$ & $152(16.88 \%)$ \\
\hline Spain & 859 & $40(4.65 \%)$ & $44(5.12 \%)$ & $18(2.09 \%)$ & $102(11.87 \%)$ \\
\hline Italy & 1430 & $115(8.04 \%)$ & 79 (5.52\%) & $75(5.52 \%)$ & $269(18.81 \%)$ \\
\hline UK & 737 & $47(6.37 \%)$ & $7(.94 \%)$ & $15(2.03 \%)$ & $69(9.36 \%)$ \\
\hline Germany & 846 & $35(4.13 \%)$ & $58(6.85 \%)$ & $26(3.07 \%)$ & $119(14.06 \%)$ \\
\hline Greece & 907 & $92(10.14 \%)$ & $71(7.82 \%)$ & $56(6.17 \%)$ & $219(24.14 \%)$ \\
\hline Total Sample & 5679 & $384(6.76 \%)$ & $320(5.63 \%)$ & $226(3.97 \%)$ & $930(16.37 \%)$ \\
\hline
\end{tabular}

(2013). Results indicate that the structure of the European Cyberbullying Intervention Project Questionnaire (ECIPQ) is composed of two factors and the model provided good fit to the data and its scales have good internal consistency, exceeding the minimum limits of Crombach index established. Thus, we could affirm that cyber-aggression and cyber-victimization become a part of cyberbullying not only from the theoretical point of view (Völlink, Bolman, Dehue, \& Jacobs, 2013), but also with empirical support. It has reinforced the conception of cyberbullying as a phenomenon of dynamic nature in which both the action of attacking and being attacked are relevant (Casas, Del Rey, \& Ortega-Ruiz, 2013; Guckin, Cummins, \& Lewis, 2010).

The different instruments which have been developed and used to measure or study cyberbullying previously are mostly limited only to cyber-aggression (Calvete et al., 2010) or only to cyber-victimization (Müller et al., 2014). Only one existing study by 
Menesini et al. (2011), shared the bi-dimensional perspective. However cyber-aggression and cyber-victimization were considered independent patterns and the study was only carried out for an exclusively Italian sample. Therefore, this questionnaire could have an advantage: the approach to present very specific actions that clearly show the conceptual boundaries of the phenomenon of cyberbullying and, therefore, showing a possible involvement as cyber-victim, cyber-aggressor, or both.

In addition, the obtained psychometric properties show a good adjustment of the instrument in a sample consisting of participants from six European countries and on a country by country basis. This fact provides robustness to the consideration that the bi-dimensionality of cyberbullying is present in samples from different countries, which reinforces the nature of the phenomenon. This is especially relevant bearing in mind that each country has its own particular habits in the use of the information and communication technologies, with differences in the type of media and virtual social networking sites used (Drabowicz, 2012). The diversity in the extent of the phenomenon is shown in the descriptive results. The utilization of one common instrument not only points out that some behaviours appear more repeatedly than others in the different countries, but also that such differences would be explained by other factors that are not covered by this study. Accordingly, it has opened a new line of cross-cultural investigation that shall cope with other differences of psychosocial nature. As a consequence of this study, we know that, at least among the participant adolescents, the prevalence of cyberbullying in diverse contexts is not that different than is shown in the studies available so far (Modecki et al., 2014). This leads us to hypothesize that said heterogeneity may be owed, as announced when reviewing the literature, to the instruments used in previous investigations (Berne et al., 2013). Thus, this instrument turns out to be a useful and validated tool to continue progressing in the knowledge of the phenomenon, mainly in two directions. On the one hand, for assessing future comparative studies with population of the participant countries and, hence, analyzing the possible differences of prevalence and the variables associated to them. On the other hand, for evaluating the interventions that are being developed to cope with cyberbullying (Malti, Ribeaud, \& Eisner, 2012) and, therefore, to develop knowledge about which practices are effective or not. As a consequence of the above, we could have evidence based practices that serve as a guarantee to adopt the necessary measures against this phenomenon which has devastating consequences for both children and adolescents and that can be even worse than traditional bullying (Gámez-Guadix, Orue, Smith, \& Calvete, 2013; Pettalia, Levin, \& Dickinson, 2013).

When interpreting the results of this study there are limitations to consider such as distortions and biases, for instance social desirability (Stone, Bachrach, Jobe, Kurtzman, \& Cain, 1999). Also, although a large sample has participated in the study, the sub-samples may not be representative samples of the six countries which are included in the study. Nevertheless, one of the major contributions of the present study is the integration into a single measurement instrument across different countries, in which ICT use may differ, but where cyberbullying is conceived in a similar way. This contribution implies a modest advance in seeking evidence based practices against cyberbullying as it offers an instrument, which can be easily administered, and that could be used for contrasting the existing cyberbullying prior to and after the psycho-educative intervention, accordingly, it can also be used for evaluating the effectiveness of the actions.

Finally, more efforts should be dedicated to achieving the validation of the ECIPQ which in turn would be an important advance for the scientific community and, particularly, to the educational policies against cyberbullying.

\section{Acknowledgments}

This work was produced as part of the project "Cyberbullying in adolescence: investigation and intervention in six European Countries" (JLS/2008/CFP1DAP12008-), funded by European Union, DAPHNE III Program Coordinated by Professor Maria Luisa Genta. And "Sexting, ciberbullying y riesgos emergentes en la red: claves para su comprensión y respuesta educativa" (EDU2013-44627-P), funded by the National Research Plan I +D. The authors are grateful for the support received.

\section{Appendix A. Supplementary material}

Supplementary data associated with this article can be found, in the online version, at http://dx.doi.org/10.1016/j.chb.2015.03.065.

\section{References}

Arsène, M., \& Raynaud, J.-P. (2014). Cyberbullying and child and adolescent psychopathology: Current state of knowledge. Neuropsychiatrie de l'Enfance et de l'Adolescence, 62(4), 249-256. http://dx.doi.org/10.1016/j.neurenf.2014.01.012.

Baek, J., \& Bullock, L. M. (2014). Cyberbullying: A cross-cultural perspective. Emotional and Behavioural Difficulties, 19(2), 226-238. http://dx.doi.org/ 10.1080/13632752.2013.849028.

Bandalos, D. L. (1993). Factors influencing cross-validation of confirmatory factor analysis models. Multivariate Behavioral Research, 28(3), 351-374. http:// dx.doi.org/10.1207/s15327906mbr2803_3.

Bentler, P. M. (1977). Factor simplicity index and transformations. Psychometrika, 42(2), 277-295. http://dx.doi.org/10.1007/BF02294054.

Bentler, P. M., \& Bonett, D. G. (1980). Significance tests and goodness of fit in the analysis of covariance structures. Psychological Bulletin, 88(3), 588-606. http:/ dx.doi.org/10.1037/0033-2909.88.3.588.

Berne, S., Frisén, A., Schultze-Krumbholz, A., Scheithauer, H., Naruskov, K., Luik, P., et al. (2013). Cyberbullying assessment instruments: A systematic review. Aggression and Violent Behavior, 18(2), 320-334. http://dx.doi.org/10.1016/ j.avb.2012.11.022.

Bollen, K. A. (1989). Structural equations with latent variables. New York: Wiley.

Brighi, A., Ortega, R., Pyzalski, J., Scheithauer, H., Smith, P. K., Tsormpatzoudis, H., et al. (2012). European cyberbullying intervention project questionnaire - ECIPQ [Unpublished questionnaire]. Retrieved from bullyingandcyber.net.

Browne, M. W., \& Cudeck, R. (1993). Alternative ways of assessing model fit. In Testing structural equation models (pp. 111-135). Newbury Park, CA: Sage.

Byrne, B. M. (2006). Structural equation modeling with Eqs: Basic concepts, applications, and programming. Routledge.

Byrne, B. M., \& Campbell, T. L. (1999). Cross-cultural comparisons and the presumption of equivalent measurement and theoretical structure: A look beneath the surface. Journal of Cross-Cultural Psychology, 30(5), 555-574. http:// dx.doi.org/10.1177/0022022199030005001.

Calvete, E., Orue, I., Estévez, A., Villardón, L., \& Padilla, P. (2010). Cyberbullying in adolescents: Modalities and aggressors' profile. Computers in Human Behavior, 26(5), 1128-1135. http://dx.doi.org/10.1016/j.chb.2010.03.017.

Casas, J. A., Del Rey, R., \& Ortega-Ruiz, R. (2013). Bullying and cyberbullying: Convergent and divergent predictor variables. Computers in Human Behavior 29(3), 580-587. http://dx.doi.org/10.1016/j.chb.2012.11.015.

Dehue, F. (2013). Cyberbullying research: New perspectives and alternative methodologies. Introduction to the Special Issue. Journal of Community $\mathcal{E}$ Applied Social Psychology, 23(1), 1-6. http://dx.doi.org/10.1002/casp.2139.

Dempsey, A. G., Sulkowski, M. L., Nichols, R., \& Storch, E. A. (2009). Differences between peer victimization in cyber and physical settings and associated psychosocial adjustment in early adolescence. Psychology in the Schools, 46(10), 962-972. http://dx.doi.org/10.1002/pits.20437.

Den Hamer, A. H., \& Konijn, E. A. (2015). Adolescents' Media exposure may increase their cyberbullying behavior: A longitudinal study. Journal of Adolescent Health, 56(2), 203-208. http://dx doi.org/10.1016/j.jadohealth.2014.09.016.

Dooley, J. J., Pyżalski, J., \& Cross, D. (2009). Cyberbullying versus face-to-face bullying. Zeitschrift für Psychologie/Journal of Psychology, 217(4), 182-188. http://dx.doi.org/10.1027/0044-3409.217.4.182.

Drabowicz, T. P. (2012). Digital Inequalities as Class Inequalities? A comparison of youth in advanced societies in-and outside Europe. European University Institute, Florence. Retrieved from http://hdl.handle.net/1814/23751.

Fenaughty, J., \& Harré, N. (2013). Factors associated with young people's successful resolution of distressing electronic harassment. Computers E Education, 61, 242-250. http://dx.doi.org/10.1016/j.compedu.2012.08.004.

Flora, D. B., \& Curran, P. J. (2004). An empirical evaluation of alternative methods of estimation for confirmatory factor analysis with ordinal data. Psychological Methods, 9(4), 466-491. http://dx.doi.org/10.1037/1082-989X.9.4.466.

Flora, D. B., Finkel, E. J., \& Foshee, V. A. (2003). Higher order factor structure of a selfcontrol test: Evidence from confirmatory factor analysis with polychoric correlations. Educational and Psychological Measurement, 63(1), 112-127. http://dx.doi.org/10.1177/0013164402239320. 
Floros, G. D., Siomos, K. E., Fisoun, V., Dafouli, E., \& Geroukalis, D. (2013). Adolescent online cyberbullying in Greece: The impact of parental online security practices, bonding, and online impulsiveness. The Journal of School Health, 83(6), 445-453. http://dx.doi.org/10.1111/josh.12049.

Gámez-Guadix, M., Orue, I., Smith, P. K., \& Calvete, E. (2013). Longitudinal and reciprocal relations of cyberbullying with depression, substance use, and problematic internet use among adolescents. Journal of Adolescent Health, 53(4), 446-452. http://dx.doi.org/10.1016/j.jadohealth.2013.03.030.

Gradinger, P., Strohmeier, D., \& Spiel, C. (2009). Traditional bullying and cyberbullying: Identification of risk groups for adjustment problems. Zeitschrift Für Psychologie/Journal of Psychology, 217(4), 205-213. http:// dx.doi.org/10.1027/0044-3409.217.4.205.

Greif, J. L., \& Furlong, M. J. (2006). The assessment of school bullying. Journal of School Violence, 5(3), 33-50. http://dx.doi.org/10.1300/J202v05n03_04.

Guckin, C. M., Cummins, P. K., \& Lewis, C. A. (2010). F2f and cyberbullying among children in Northern Ireland: Data from the Kids Life and Times Surveys. Psychology, Society E Education, 2(2), 83-96.

Heirman, W., \& Walrave, M. (2008). Assessing concerns and issues about the mediation of technology in cyberbullying. Retrieved from <http://ir.anet.ua.ac.be/irua/ handle/10067/731800151162165141>.

Holgado-Tello, F. P., Chacón-Moscoso, S., Barbero-García, I., \& Vila-Abad, E. (2010). Polychoric versus Pearson correlations in exploratory and confirmatory factor analysis of ordinal variables. Quality \& Quantity, 44(1), 153-166. http:// dx.doi.org/10.1007/s11135-008-9190-y.

Jöreskog, K. G. (1994). On the estimation of polychoric correlations and their asymptotic covariance matrix. Psychometrika, 59(3), 381-389. http://dx.doi.org/ 10.1007/BF02296131.

Jöreskog, K. G., \& Sörbom, D. (2012). Lisrel 9.1. Skokie: Scientific Software International, Inc. Retrieved from <http://www.ssicentral.com/lisrel/>.

Låftman, S. B., Modin, B., \& Östberg, V. (2013). Cyberbullying and subjective health. A large-scale study of students in Stockholm, Sweden. Children and Youth Services Review, 35(1), 112-119. http://dx.doi.org/10.1016/j.childyouth. 2012.10.020.

Law, D. M., Shapka, J. D., Domene, J. F., \& Gagné, M. H. (2012). Are cyberbullies really bullies? An investigation of reactive and proactive online aggression. Computers in Human Behavior, 28(2), 664-672. http://dx.doi.org/10.1016/j.chb.2011.11.013.

Law, D. M., Shapka, J. D., Hymel, S., Olson, B. F., \& Waterhouse, T. (2012). The changing face of bullying: An empirical comparison between traditional and internet bullying and victimization. Computers in Human Behavior, 28(1), 226-232. http://dx.doi.org/10.1016/j.chb.2011.09.004.

Lorenzo-Seva, U. (2003). A factor simplicity index. Psychometrika, 68(1), 49-60. http://dx.doi.org/10.1007/BF02296652.

Lorenzo-Seva, U., \& Ferrando, P. J. (2006). FACTOR: A computer program to fit the exploratory factor analysis model. Behavior Research Methods, 38(1), 88-91.

Malti, T., Ribeaud, D., \& Eisner, M. (2012). Effectiveness of a universal school-based social competence program: The role of child characteristics and economic factors. International Journal of Conflict and Violence, 6(2), 249-259.

Menesini, E., \& Nocentini, A. (2009). Cyberbullying definition and measurement. Zeitschrift für Psychologie/Journal of Psychology, 217(4), 230-232. http:// dx.doi.org/10.1027/0044-3409.217.4.230.

Menesini, E., Nocentini, A., \& Calussi, P. (2011). The measurement of cyberbullying: Dimensional structure and relative item severity and discrimination. Cyberpsychology, Behavior, and Social Networking, 14(5), 267-274. http:// dx.doi.org/10.1089/cyber.2010.0002.

Modecki, K. L., Minchin, J., Harbaugh, A. G., Guerra, N. G., \& Runions, K. C. (2014). Bullying prevalence across contexts: A meta-analysis measuring cyber and traditional bullying. Journal of Adolescent Health, 55(5), 602-611. http:// dx.doi.org/10.1016/j.jadohealth.2014.06.007.

Morata-Ramírez, M. de los Á., \& Holgado-Tello, F. P. (2013). Construct validity of likert scales through confirmatory factor analysis: A simulation study comparing different methods of estimation based on pearson and polychoric correlations. International Journal of Social Science Studies, 1(1), 54-61. http:// dx.doi.org/10.11114/ijsss.v1i1.27.

Müller, C. R., Pfetsch, J., \& Ittel, A. (2014). Ethical media competence as a protective factor against cyberbullying and cybervictimization among German school students. Cyberpsychology, Behavior and Social Networking, 17(10), 644-651. http://dx.doi.org/10.1089/cyber.2014.0168.

Nocentini, A., Calmaestra, J., Schultze-Krumbholz, A., Scheithauer, H., Ortega, R., \& Menesini, E. (2010). Cyberbullying: Labels, behaviours and definition in three European countries. Australian Journal of Guidance and Counselling, 20(2), $129-142$.

Olsson, U. (1979). Maximum likelihood estimation of the polychoric correlation coefficient. Psychometrika, 44(4), 443-460. http://dx.doi.org/10.1007/BF02296207.

Olweus, D. (1993). Bullying at school: What we know and what we can do. Oxford, UK, Cambridge, USA: Blackwell.

Olweus, D. (2012). Cyberbullying: An overrated phenomenon? European Journal of Developmental Psychology, 9(5), 520-538.
Olweus, D. (2013). School bullying: Development and some important challenges. In S. NolenHoeksema (Ed.). Annual review of clinical psychology (Vol. 9, pp. 751-780). Palo Alto: Annual Reviews.

Olweus, D. (1999). Sweden. In P. K. Smith, Y. Morita, J. Junger-Tas, D. Olweus, R. Catalano, \& P. Slee (Eds.), The nature of school bullying: A cross-national perspective (pp. 7-27). London \& New York: Routledge.

Perren, S. Corcoran, L., Cowie, H., Dehue, F., Garcia, D., Mc Guckin, C., et al. (2012) Tackling cyberbullying: Review of empirical evidence regarding successful responses by students, parents, and schools. International Journal of Conflict and Violence, 6(2), 283-293.

Perren, S., Dooley, J., Shaw, T., \& Cross, D. (2010). Bullying in school and cyberspace: Associations with depressive symptoms in Swiss and Australian adolescents. Child and Adolescent Psychiatry and Mental Health, 4, 28. http://dx.doi.org/ 10.1186/1753-2000-4-28.

Pettalia, J. L., Levin, E., \& Dickinson, J. (2013). Cyberbullying: Eliciting harm without consequence. Computers in Human Behavior, 29(6), 2758-2765. http:/l dx.doi.org/10.1016/j.chb.2013.07.020.

Pornari, C. D., \& Wood, J. (2010). Peer and cyber aggression in secondary school students: The role of moral disengagement, hostile attribution bias, and outcome expectancies. Aggressive Behavior, 36(2), 81-94. http://dx.doi.org/ $10.1002 / a b .20336$

Pyzalski, J. (2012). From cyberbullying to electronic aggression: Typology of the phenomenon. Emotional and Behavioural Difficulties, 17(3-4), 305-317.

Sabella, R. A., Patchin, J. W., \& Hinduja, S. (2013). Cyberbullying myths and realities. Computers in Human Behavior, 29(6), 2703-2711. http://dx.doi.org/10.1016/ j.chb.2013.06.040.

Satorra, A., \& Bentler, P. M. (2001). A scaled difference chi-square test statistic for moment structure analysis. Psychometrika, 66(4), 507-514. http://dx.doi.org/ 10.1007/BF02296192.

Slonje, R., \& Smith, P. K. (2008). Cyberbullying: Another main type of bullying? Scandinavian Journal of Psychology, 49(2), 147-154. http://dx.doi.org/10.1111/ j.1467-9450.2007.00611.x.

Slonje, R., Smith, P. K., \& Frisén, A. (2013). The nature of cyberbullying, and strategies for prevention. Computers in Human Behavior, 29(1), 26-32. http:// dx.doi.org/10.1016/j.chb.2012.05.024.

Smith, P. K., Del Barrio, C., \& Tokunaga, R. (2013). Definitions of bullying and cyberbullying: How useful are the terms? In S. Bauman, J. Walker, \& D. Cross (Eds.), Principles of cyberbullying research: Definition, methods, and measures (pp. 64-86). New York \& London: Routledge.

Smith, P. K., Thompson, F., \& Davidson, J. (2014). Cyber safety for adolescent girls: bullying, harassment, sexting, pornography, and solicitation. Current Opinion in Obstetrics and Gynecology, 26(5), 360-365. http://dx.doi.org/10.1097/ GCO.0000000000000106.

Stone, A. A., Bachrach, C. A., Jobe, J. B., Kurtzman, H. S., \& Cain, V. S. (Eds.). (1999). The science of self-report: Implications for research and practice. London: Psychology Press.

Tokunaga, R. S. (2010). Following you home from school: A critical review and synthesis of research on cyberbullying victimization. Computers in Human Behavior, 26(3), 277-287. http://dx.doi.org/10.1016/j.chb.2009.11.014.

Tynes Rose, C. A., \& Williams, D. R. (2010). The development and validation of the Online Victimization Scale for Adolescents. Cyberpsychology: Journal of Psychosocial Research on Cyberspace, 4(2), 1-15.

Vandebosch, H., \& Van Cleemput, K. (2008). Defining cyberbullying: A qualitative research into the perceptions of youngsters. CyberPsychology \& Behavior, 11(4), 499-503. http://dx.doi.org/10.1089/cpb.2007.0042.

Vivolo-Kantor, A. M., Martell, B. N., Holland, K. M., \& Westby, R. (2014). A systematic review and content analysis of bullying and cyber-bullying measurement strategies. Aggression and Violent Behavior, 19(4), 423-434. http://dx.doi.org/ 10.1016/j.avb.2014.06.008.

Völlink, T., Bolman, C. A., Dehue, F., \& Jacobs, N. C. (2013). Coping with cyberbullying: Differences between victims, bully-victims and children not involved in bullying. Journal of Community and Applied Social Psychology, 23(1), 7-24. http://dx.doi.org/10.1002/casp.2142.

Wu, W., West, S. G., \& Taylor, A. B. (2009). Evaluating model fit for growth curve models: Integration of fit indices from SEM and MLM frameworks. Psychological Methods, 14(3), 183-201. http://dx.doi.org/10.1037/a0015858.

Yang, A., \& Salmivalli, C. (2013). Different forms of bullying and victimization: Bully-victims versus bullies and victims. European Journal of Developmental Psychology, 10(6), 723-738. http://dx.doi.org/10.1080/17405629.2013.793596.

Ybarra, M. L., \& Mitchell, K. J. (2008). How risky are social networking sites? A comparison of places online where youth sexual solicitation and harassment occurs. Pediatrics, 121(2), e350-e357. http://dx.doi.org/10.1542/peds.20070693.

Ybarra, M. L., Mitchell, K. J., \& Korchmaros, J. D. (2011). National trends in exposure to and experiences of violence on the internet among children. Pediatrics, 128(6), e1376-e1386. http://dx.doi.org/10.1542/peds.2011-0118. 